ORIGINAL ARTICLE

\title{
Multiplicity of medication safety terms, definitions and functional meanings: when is enough enough?
}

\author{
K H Yu, R L Nation, M J Dooley
}

Qual Saf Health Care 2005;14:358-363. doi: 10.1136/qshc.2005.014159

See end of article for authors' affiliations

Correspondence to:

Professor R L Nation,

Centre for Medication

Safety, Department of

Pharmacy Practice,

Victorian College of

Pharmacy, Monash

University, 381 Royal

Parade, Parkville, Victoria

3052, Australia; Roger.

Nation@vcp.monash.edu.

au

Accepted for publication 30 July 2005 definitions used by organisations involved in medication safety and to Objectives: To identify the terms and definitions used by organisations involved in medicatic
examine differences in functional meaning using a novel scenario assignment method.

Methods: Medication safety related terms and definitions were sought from websites of organisations associated with medication safety. The functional meanings of terms and definitions were analysed and compared using a scenario assignment method where each definition found was assessed against four scenarios with a central theme.

Main outcome measures: Medication safety related terms and definitions currently in use, similarities and differences in their functional meanings, and practical implications of the use of these terms and definitions.

Results: Thirty three of 160 websites searched were found to have one or more definitions for medication safety related terms. Twenty five different terms with 119 definitions were found. The most frequently defined groups of terms were "adverse event" (8 different definitions), "error" ( $=9$ ), "near miss" $(n=12)$, "adverse reaction" ( $n=8)$, and "incident" $(n=4)$. Substantial diversity of functional meanings of definitions was demonstrated using the scenario-assignment method. Of the five groups of frequently defined terms, definitions within the "adverse event", "near miss", and "incident" groups resulted in three functional meanings each, while two functional meanings resulted for "error" and "adverse reaction". Conclusion: The multiplicity of terms, definitions and, most importantly, functional meanings demonstrates the urgent need for agreement on standardisation of nomenclature describing medication related occurrences. This is an essential prerequisite to enable meaningful analysis of incidence data and development of medication safety improvement strategies.
$M$ edication safety is a common and important health priority in many countries. Several studies from various countries have reported that $3.7-16.6 \%$ of total hospital admissions were associated with adverse events, a substantial proportion of which were attributed to medication use. ${ }^{1-6}$

Strategies to mitigate medication errors rely critically on the collection of information on individual events as this allows the causes to be identified (through root cause analysis) and trends to be tracked. The importance of data collection extends to applications such as identification of system problems that contribute to medication related occurrences; evaluation of strategies to improve medication safety; comparison of incidence data locally, nationally and internationally; and, as an educational resource to increase awareness of health professionals to mitigate the likelihood of future medication related occurrences. Incident reporting plays a significant part in information collection, especially in a hospital setting, but one study comparing methods of detecting medication errors found as little as $0.04 \%$ of medication errors being reported via this method. ${ }^{7}$ One of the barriers to reporting found by a recent study published in this journal was the need for clearer definitions of reportable events. $^{8}$

The range of possible events that could compromise patient safety has resulted in a multiplicity of terms to categorise these events. Unfortunately, this problem is further compounded by the fact that multiple terms are used for the classification of the same event and there appear to be many individual definitions and interpretations associated with this plethora of terms. ${ }^{9}$ For example, "near miss" has been used interchangeably with terms such as "potential adverse drug event" and "potential error"; among this myriad of terms, "near miss" can refer to an error that was intercepted before it reached the patient ${ }^{10}{ }^{11}$ or to one that simply did not result in a negative patient outcome. ${ }^{12}{ }^{13}$ While the existence of the multiplicity of terms and definitions has been recognised, ${ }^{8}{ }^{13-19}$ the practical implications that arise when attempting to apply the terms and definitions to the documentation and classification of medication safety events have not been fully explored.

The aims of this study were to identify the terms and definitions used by organisations involved in medication safety and, in particular, to examine differences in interpretation or functional meaning using a novel scenario assignment method.

\section{METHODS}

\section{Search for terms and definitions}

Medication safety related terms and definitions were found by an electronic search of websites of organisations associated with medication safety in September 2003. The Institute for Safe Medication Practices (ISMP) was arbitrarily chosen as a starting point and links to other organisations found on the ISMP website were followed. The newly identified websites were browsed for relevance and organisations unrelated to medication or patient safety were disregarded. The "links" section of each newly identified organisation was then followed. The process was continued until no new organisations were identified. Each website identified from the compilation process was then searched using one or both of the following methods.

Search using internal search engine

"Adverse event", "medication safety", "patient safety", "error", "glossary", and "definition" were entered as 
separate keywords into the internal search engine of each website and the resultant web pages were browsed for medication safety terms and definitions. "Adverse event" and "error" were chosen as search terms because it was believed they would yield information not only in the broader context of patient safety and medical errors but also in relation to the more specific "adverse drug events" and "medication errors" related to medication safety. "Glossary" and "definition" were included as keywords to find pages within the website which may specifically contain medication safety terms and definitions.

\section{Search using publicly available electronic}

documents within the website

Electronic publications that did not require password or membership access were browsed for medication safety terms and definitions. Documents potentially relevant to medication and/or patient safety were browsed with particular attention to sections such as appendices and glossaries as these often contained terms and definitions.

Websites of organisations were excluded from the search if they did not allow at least one of the above searches to be performed.

Terms and definitions identified were tabulated according to the organisation from which they were sourced. Elements within a definition that were deemed important to its interpretation were highlighted. Each definition was recorded individually in cases where there were multiple definitions for one medication safety term.

Terms with similar definitions were grouped together into clusters. The definitions within each of these clustered groups were then examined in detail to identify the main themes depicted. Thematic trends were compared within and across the clustered groups for similarities and differences.

\section{Interpretations of terms and definitions}

Four scenarios were devised to assess the functional meanings of the terms and definitions (fig 1). All four scenarios revolve around a penicillin hypersensitivity reaction. Scenario A involves a patient with no history of penicillin hypersensi-

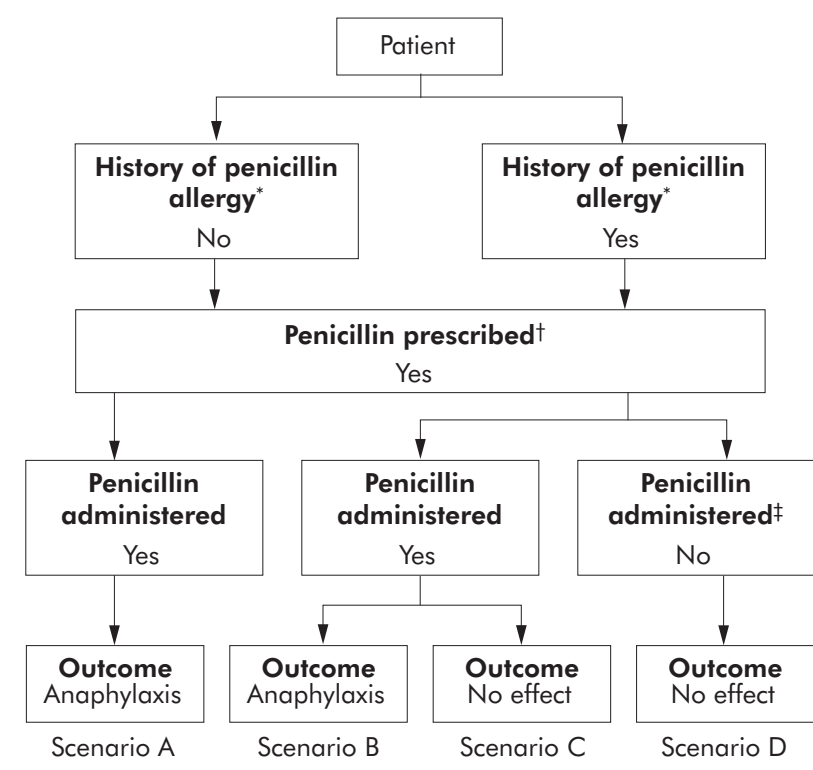

Figure 1 Four scenarios used in the scenario assignment process. *The allergy history was clearly documented in the patient's medical record which was easily accessible to the health carers. †The penicillin used in this case was not a treatment modality where no reasonable alternative existed. $¥$ The penicillin was not administered because the patient's penicillin allergy was detected before administration. tivity reaction who received a prescribed dose of penicillin which resulted in an anaphylactic episode. In scenarios B, C and $\mathrm{D}$ the patient has a known and documented hypersensitivity reaction to penicillin but it was still prescribed. In scenario $\mathrm{B}$ the patient was administered the penicillin and this resulted in an anaphylactic episode. In scenario $C$ the drug was administered but the patient fortuitously experienced no effect. The patient in scenario D was also prescribed penicillin but the prior hypersensitivity was detected and therefore the drug was not administered.

All four scenarios were applied to each of the definitions and scenario assignment was conducted by KHY. Scenarios that were within the boundary of the interpretation of a particular definition were assigned ticks $(\sqrt{ })$ and scenarios that did not fall within the parameters of the definition were assigned crosses $(x)$. The scenario assignments for definitions of the same term were compared to assess the consistency of the functional meanings of the definitions. It was deemed that, for a given term, assignments of each of the four scenarios across the various definitions should be identical if the functional meanings of the definitions were the same.

An inter-rater reliability assessment was performed by an independent pharmacist with knowledge and experience in this field, where she undertook the scenario assignment process for 25 definitions randomly selected from the list generated from the search. To avoid any preconceived meanings for the definitions, only the wording of the definitions was made available to the independent assessor. The scenario assignments of the two assessors (KHY and the independent pharmacist) were compared for agreement and inter-rater reliability (kappa statistic) using SPSS Version 11.5 .

\section{RESULTS}

Websites of 160 organisations involved in medication safety were electronically searched for terms and definitions used in the field. Thirty three of these organisations were found to have one or more definitions for medication safety terms

Table 1 Number of medication safety related terms and corresponding definitions

\begin{tabular}{lc}
\hline Term & $\begin{array}{c}\text { No of definitions } \\
\text { (total) }\end{array}$ \\
\hline Adverse drug event & 10 \\
Adverse drug reaction & 11 \\
Adverse effect & 1 \\
Adverse event & 21 \\
Adverse incident & 2 \\
Adverse medication event & 1 \\
Adverse reaction & 3 \\
Critical event & 1 \\
Critical incident & 1 \\
Error & 13 \\
Incident & 8 \\
Medical error & 3 \\
Medication error & 7 \\
Medication incident & 1 \\
Near miss & 8 \\
Potential adverse drug event & 4 \\
Potential adverse event & 1 \\
Potential error & 3 \\
Preventable adverse drug event & 2 \\
Preventable adverse event & 2 \\
Sentinel event & 5 \\
Serious adverse event & 2 \\
Side effect & 6 \\
Significant adverse event & 1 \\
Unpreventable adverse event & 2 \\
Total number of terms $=25$ & \\
\hline & \\
& 119 \\
\hline
\end{tabular}


Table 2 Most commonly defined medication safety terms

\begin{tabular}{|c|c|c|c|c|}
\hline Group and related terms & Totc & of definitions & $\begin{array}{l}\text { No of different } \\
\text { definitions }\end{array}$ & $\begin{array}{l}\text { No of differen } \\
\text { functional } \\
\text { meanings* }\end{array}$ \\
\hline Adverse event & & 32 & 8 & 3 \\
\hline "Adverse event" & 21 & & & \\
\hline "Adverse drug event" & 10 & & & \\
\hline "Adverse medication event" & 1 & & & \\
\hline Error & & 23 & 9 & 2 \\
\hline "Error" & 13 & & & \\
\hline "Medical error" & 3 & & & \\
\hline "Medication error" & 7 & & & \\
\hline Near miss & & 16 & 12 & 3 \\
\hline "Near miss" & 8 & & & \\
\hline "Potential adverse event" & 1 & & & \\
\hline "Potential adverse drug event" & 4 & & & \\
\hline "Potential error" & 3 & & & \\
\hline Adverse reaction & & 14 & 8 & 2 \\
\hline "Adverse reaction" & 3 & & & \\
\hline "Adverse drug reaction" & 11 & & & \\
\hline Incident & & 9 & 4 & 3 \\
\hline "Incident" & 8 & & & \\
\hline "Medication incident" & 1 & & & \\
\hline
\end{tabular}

Table 3 Twelve different definitions and three functional meanings found for "near miss" and related terms

\begin{tabular}{|c|c|c|c|c|c|}
\hline \multirow[b]{2}{*}{ Organisation } & \multirow[b]{2}{*}{ Terms and definitions } & \multicolumn{4}{|c|}{ Scenario } \\
\hline & & A & B & C & D \\
\hline $\begin{array}{l}\text { Australian Council for Safety and } \\
\text { Quality in Health Care (ACSQHC) }\end{array}$ & $\begin{array}{l}\text { "Near miss": } \\
\text { An incident that did not cause harm. }\end{array}$ & $x$ & $x$ & $\sqrt{ }$ & $\checkmark$ \\
\hline $\begin{array}{l}\text { American Society for Healthcare } \\
\text { Risk Management (ASHRM) }\end{array}$ & $\begin{array}{l}\text { "Near miss": } \\
\text { Any process variation which did not affect the outcome, but for which a } \\
\text { recurrence carries a significant chance of a serious adverse outcome. }\end{array}$ & $x$ & $x$ & $\sqrt{ }$ & l \\
\hline $\begin{array}{l}\text { British Medical } \\
\text { Association (BMA) }\end{array}$ & $\begin{array}{l}\text { "Near miss": } \\
\text { A situation in which an event or omission, or sequence of events or omissions, } \\
\text { could have resulted in injury to a patient if allowed to progress further or in } \\
\text { different circumstances. }\end{array}$ & $x$ & $x$ & $\sqrt{ }$ & l \\
\hline Health Canada & $\begin{array}{l}\text { "Near miss": } \\
\text { An event or situation that could have resulted in an accident, injury or illness, } \\
\text { but did not, either by chance or through timely intervention. }\end{array}$ & $x$ & $x$ & $\sqrt{ }$ & l \\
\hline $\begin{array}{l}\text { Royal College of Physicians and } \\
\text { Surgeons of Canada (RCPSC) }\end{array}$ & $\begin{array}{l}\text { "Near miss": } \\
\text { A situation in which the patient had a narrow escape from a serious } \\
\text { complication. }\end{array}$ & $x$ & $x$ & $\sqrt{ }$ & l \\
\hline UK Department of Health & $\begin{array}{l}\text { "Near miss": } \\
\text { A situation in which an event or omission, or a sequence of events or } \\
\text { omissions, arising during clinical care fails to develop further, whether or } \\
\text { not as a result of compensating action, thus preventing injury to a patient. }\end{array}$ & $x$ & $x$ & $\sqrt{ }$ & l \\
\hline $\begin{array}{l}\text { Association of Perioperative } \\
\text { Registered Nurses (AORN) }\end{array}$ & $\begin{array}{l}\text { "Potential adverse drug event": } \\
\text { An incident with potential for injury related to a drug. }\end{array}$ & $x$ & $x$ & $\sqrt{ }$ & l \\
\hline Health Canada & $\begin{array}{l}\text { "Potential adverse drug event": } \\
\text { An incident in which an error was made but no harm occurred. }\end{array}$ & $x$ & $x$ & $\sqrt{ }$ & l \\
\hline $\begin{array}{l}\text { Institute for Healthcare } \\
\text { Improvement (IHI) }\end{array}$ & $\begin{array}{l}\text { "Potential adverse drug event": } \\
\text { Occurrence of a medication error that could result in an adverse drug event } \\
\text { but does not because of intervention or chance. }\end{array}$ & $x$ & $x$ & $\sqrt{ }$ & l \\
\hline $\begin{array}{l}\text { Association of Perioperative } \\
\text { Registered Nurses (AORN) }\end{array}$ & $\begin{array}{l}\text { "Potential adverse event": } \\
\text { An error of medical management that does not result in injury ("near misses"). }\end{array}$ & $x$ & $x$ & l & l \\
\hline $\begin{array}{l}\text { Agency for Healthcare Research } \\
\text { and Quality (AHRQ) }\end{array}$ & $\begin{array}{l}\text { "Potential adverse drug event": } \\
\text { A medication error or other drug-related mishap that reached the patient, but } \\
\text { happened not to produce harm. }\end{array}$ & $x$ & $x$ & $\sqrt{ }$ & $x$ \\
\hline $\begin{array}{l}\text { American Society of Hospital } \\
\text { Pharmacists (ASHP) }\end{array}$ & $\begin{array}{l}\text { "Potential error": } \\
\text { A mistake in prescribing, dispensing, or planned medication administration } \\
\text { that is detected and corrected through intervention (by another health care } \\
\text { provider or patient) before actual medication administration. }\end{array}$ & $x$ & $x$ & $x$ & $\checkmark$ \\
\hline
\end{tabular}


Table 4 Two definitions for the same term from the Australian Council for Safety and Quality in Health Care* leading to different scenario assignments

Definition
"Side effect" (1):
An effect, other than that intended, produced by an agent in absence of error.
"Side effect" (2):
Any unintended effect of a medicine occurring at doses normally used in people
which is related to the pharmacological properties of the drug.
"Error" (1):

Bold text $=$ keywords within the definition upon which the scenario assignment decisions were made. *Definition 1 in each case is from the First National Report on Patient Safety (2001) and definition 2 is from the Second National Report on Patient Safety: Improving Medication Safety (2002).

within their websites (see Appendix 1). Twenty five different medication safety terms and 119 definitions were found (table 1).

When definitions of terms were compared with others within their clustered group, diversity could be seen in both the definitions and their individual interpretations. The diversity of definitions is shown by comparing the original number of the definitions found in the search with the reduced number after similarly worded definitions were combined (table 2). The greatest degree of diversity resided with "near miss" and related terms, with 16 definitions reduced to 12 , while the "adverse event" and related terms had the least diversity with 32 definitions reduced to 8 .

Diversity in the individual interpretations of definitions was demonstrated by the inconsistent scenario assignments, which was present in all five of the most commonly defined groups of terms (table 2). Using "near miss" and the related group of terms as examples again, it was found that there were 12 differently worded definitions but these 12 could be interpreted as having three separate functional meanings, as illustrated by the number of scenario assignment permutations (table 3).

Scenarios C and D were both considered as "near misses" in 10 definitions of "near miss" and related terms because these 10 definitions had one or more of the following themes which were also present in scenarios C and D: (1) no harm resulted; (2) could have resulted in harm if the event recurred; (3) occurrence was a result of an error; and (4) the absence of harm was by chance or due to timely intervention. The remaining two definitions were specific about whether the occurrence needed to have reached the patient for it to be considered a "near miss"- that is, "reached the patient but happened not to produce harm" (scenario C; definition of "potential adverse drug event" from the Agency for Healthcare Research and Quality) as compared to "detected and corrected through intervention before actual medication administration" (scenario D; definition of "potential error" from the American Society of Hospital Pharmacists).

There were two instances where the one organisation (the Australian Council for Safety and Quality in Health Care) has published two different definitions for the terms "side effect" and "error" leading to different scenario assignments in both cases (table 4).

In the first definition of "side effect", only scenario A was considered as a "side effect" as it is the only scenario with an "absence of error". In the second definition of "side effect" from the same organisation, however, both scenarios A and B were considered as "side effects" as the anaphylactic episodes resulting from the penicillin administration were "unintended" and were "related to the pharmacological properties of the drug". The difference in scenario assignment for the two "error" definitions occurred with scenario D. Scenario D was not considered an "error" in the first definition because, by withholding the penicillin administration, it did not satisfy the "failure to complete an action as intended" section of the definition. The intended action in this scenario was to treat the patient's infection safely and appropriately; therefore, by avoiding the actual administration of penicillin (despite the fact that it was prescribed), this action was still fulfilled. Scenario D was regarded as an "error" according to the second definition because there was a "potential to lead to harm". The fact that the prescriber did not check the patient's allergy status before prescribing constituted "an act of omission or commission".

Of the list of definitions generated from the search, 25 were randomly selected for determination of inter-rater reliability. The agreement between the two assessors (KHY and independent pharmacist) in scenarios A-D was 0.96, 0.96, 0.92 , and 0.88 , respectively, with good to very good inter-rater reliabilities $(\kappa=0.92,0.88,0.83$ and 0.73 , respectively).

\section{DISCUSSION}

The most important finding of this study is that our novel scenario assignment methodology demonstrated the ambiguities and variability of the medication safety related terms and definitions currently in use. Thus, the classification of medication related occurrences using existing terminology can only be described as haphazard.

The confusion that exists with regard to the taxonomy used in the medication safety field is by no means a new problem. In the 1980s Manasse ${ }^{20}$ recognised that common terms were developed over the years to convey negative consequences and probable risks of drug treatment but that they were not often distinguished in definition or usage. In a 1986 survey Case and Guzetti ${ }^{21}$ found 59 different definitions of "adverse drug reaction" used in 76 hospitals. Almost two decades on, there is still no universally accepted definition for "adverse drug reaction". ${ }^{14}{ }^{16}$ An example from the present study was with "near miss" and related terms, where 12 of 16 definitions had significantly different wording and multiple themes. This served to highlight the fact that organisations within this field have not yet reached a consensus as to what constitutes a "near miss". 


\section{Diversity in functional meanings}

Attempts have been made by stakeholders and researchers to develop methods to illustrate and tackle the problems associated with terms and definitions used in the medication safety field. These have included the use of diagrams, ${ }^{22-24}$ case studies, ${ }^{16}$ and consultation strategy. ${ }^{9}$ We have employed an original approach, the scenario assignment method, to examine and exemplify the diversity of functional meanings within definitions. Four scenarios were devised to revolve around the central concept of penicillin hypersensitivity to reflect different circumstances and outcomes. A major advantage of this method is that it provides a means of assessment of the possible conflict in the functional meanings of the various definitions for any given term. As the results of this study demonstrated, the definitions currently used in practice are less than satisfactory, with all five of the most frequently defined medication safety terms having at least two functional meanings as indicated by the different permutations of scenario assignments. This was clearly exemplified by the "near miss" group of terms. Not only were there three functional meanings derived from 16 definitions, the disparities in functional meanings of "near miss" and related terms were illustrated by the inter-rater reliability test, with five disagreements pertaining to the "near miss" scenarios (scenarios C and D). This is especially remarkable considering that there were only seven disagreements across the 100 scenario assignments. The confusion associated with medication safety related terminology was further compounded where the one organisation (the Australian Council for Safety and Quality in Health Care) has published two different definitions for the terms "error" and "side effect", each in turn leading to separate functional meanings.

We acknowledge that the compilation of terms and definitions is not exhaustive as the intention of this study was to demonstrate the extent of diversity that exists within the medication safety arena. The fact that this study may have underestimated the number of functional meanings used in practice for any given term only accentuates the impact of our findings. This diversity in the terms, definitions, and functional meanings is likely to be even larger than we have demonstrated when one considers that many health services and hospitals have developed their own versions. ${ }^{21} 25$

The scenario assignment process was subjective and it was therefore possible to obtain different results from a different scenario assigner according to his or her interpretation of particular definitions. However, high inter-rater agreement indicated that this was unlikely to have been a significant issue. The study has provided evidence that the novel scenario assignment method is successful in demonstrating the diverse functional meanings of the various definitions of a given term. This method also served to exemplify the significant difficulties that can arise in the practical use of the existing terms and definitions.

\section{Implications of the study}

This study has shown the diversity present in both the medication safety terms and definitions used in the healthcare arena. Even more significant are the inconsistencies in functional meanings among this multiplicity of terms and definitions. While some common themes were identified within groups of related terms, the results of the scenario assignment showed that neither the terms nor definitions used to describe occurrences related to medication use are uniform. The ambiguities exist to such an extent that whether a particular medication related occurrence is classified as an "adverse event", an "error", a "near miss", an "adverse reaction" or an "incident" is highly dependent on the definition chosen. Furthermore, these definitions may be even more unsatisfactory when they are used to classify medication related occurrences that are much more complex than the scenarios devised for this study.

It is evident that an urgent need exists for a universal language that allows health professionals to understand and communicate all aspects of medication safety. This language needs to be "operationalised", ${ }^{20}$ combining a standardised set of carefully worded, succinct, clearly qualified, and easy to comprehend definitions. We are not suggesting that a completely new series of definitions be devised to substitute those currently in use. Rather, collaboration among individuals, groups and organisations attempting to address this issue may be possible, beginning with a review of existing definitions by representative expert bodies and with input from various key stakeholders. Barriers to the acceptance and uniform adoption of standardised definitions across institutions should be investigated. Strategies formulated to address this issue must engage health professionals at the grass roots level and simultaneously promote partnerships among medication safety interest groups. The need for people and groups with differing interests and requirements to use medication safety terms and definitions (such as those working in quality and safety management versus those in the regulatory and pharmacovigilance areas) should be acknowledged and cooperative approaches should be sought to ameliorate the diversity and confusion. Agreement on standardised medication safety nomenclature is essential for the analysis of medication safety related occurrences.

\section{ACKNOWLEDGEMENTS}

The authors thank Ms Tam Vuong (Monash University) who undertook the inter-rater reliability assessments for this research.

\section{Authors' affiliations}

K H Yu, R L Nation, M J Dooley, Centre for Medication Safety, Department of Pharmacy Practice, Victorian College of Pharmacy, Monash University, Victoria, Australia

M J Dooley, Pharmacy Department, Bayside Health, Victoria, Australia Competing interests: None.

\section{APPENDIX 1 ORGANISATIONS WITH MEDICATION SAFETY RELATED TERMS AND DEFINITIONS ON THEIR WEBSITE}

- Adverse Drug Reaction Advisory Committee (ADRAC): Australia

- Agency for Healthcare Research and Quality (AHRQ): USA

- American Society of Consultant Pharmacists (ASCP): USA

- American Society of Healthcare Risk Management (ASHRM): USA

- American Society of Health-system Pharmacists (ASHP): USA

- Association of Perioperative Registered Nurses (AORN): USA

- Australian Capital Territory Health (ACT Health): Australia

- Australian Council for Safety and Quality in Health Care (ACSQHC): Australia

- Australian Patient Safety Foundation (APSF): Australia

- British Medical Association (BMA): UK

- Canadian Institute for Health Information (CIHI): Canada

- Commission for Healthcare Improvement (CHI): UK

- Commonwealth Department of Health and Aging: Australia

- ECRI (formerly the Emergency Care Research Institute): USA 
- Food and Drug Administration (FDA): USA

- Health Canada: Canada

- Institute for Healthcare Improvement (IHI): USA

- Institute for Safe Medication Practices (ISMP): USA

- Institute of Medicine (IOM): USA

- Joint Commission on Accreditation of Healthcare Organisations (JCAHO): USA

- National Academy for State Health Policy (NASHP): USA

- National Association of Public Hospitals and Health Systems (NAPH): USA

- National Center for Patient Safety (NCPS): USA

- National Committee for Quality Assurance (NCQA): USA

- National Coordinating Council for Medication Error Reporting and Prevention (NCCMERP): USA

- National Patient Safety Agency (NPSA): UK

- New South Wales Therapeutic Advisory Group (NSW TAG): Australia

- Northern Sydney Health (NSH): Australia

- Quality Interagency Coordination Task Force (QuIC): USA

- The Royal College of Physicians and Surgeons of Canada (RCPSC): Canada

- United Kingdom Department of Health: UK

- Victorian Drug Usage and Advisory Committee (VDUAC): Australia

- World Health Organisation (WHO): International

\section{REFERENCES}

1 Vincent C, Neale G, Woloshynowych M. Adverse events in British hospitals: preliminary retrospective record review. BMJ 2001;322:517-9.

2 Brennan TA, Leape LL, Laird NM, et al. Incidence of adverse events and negligence in hospitalized patients. Results of the Harvard Medical Practice Study I. N Engl J Med 1991;324:370-6.

3 Wilson RM, Runciman WB, Gibberd RW, et al. The Quality in Australian Health Care Study. Med J Aust 1995;163:458-71.

4 Wilson RM, Harrison BT, Gibberd RW, et al. An analysis of the causes of adverse events from the Quality in Australian Health Care Study. Med J Aust 1999; 170:411-5.

5 Davis P, Lay-Yee R, Briant R, et al. Adverse events in New Zealand public hospitals: principal findings from a national survey. New Zealand Ministry of Health, 2001
6 Baker GR, Norton PG, Flintoft V, et al. The Canadian Adverse Events Study: the incidence of adverse events among hospital patients in Canada. Can Med Assoc J 2004; 170:1678-86.

7 Flynn EA, Barker KN, Pepper GA, et al. Comparison of methods for detecting medication errors in 36 hospitals and skilled-nursing facilities. Am J Health Syst Pharm 2002;59:436-46.

8 Dean B. Adverse drug events: what's the truth? Qual Saf Health Care 2003;12:165-6.

9 Australian Council for Safety and Quality in Health Care. Shared meanings: consultation toward a common vocabulary of key health care safety terms. Available at http://www.safetyandquality.org.au/definitions/smhome.htm (accessed 10 August 2004).

10 Schmidt CE, Bottoni T. Improving medication safety and patient care in the emergency department. J Emerg Nurs 2003;29:12-6.

11 Chaudhry SI, Olofinboba KA, Krumholz HM. Detection of errors by attending physicians on a general medicine service. J Gen Intern Med 2003; 18:595-600

12 Uribe CL, Schweikhart SB, Pathak DS, et al. Perceived barriers to medicalerror reporting: an exploratory investigation. J Healthc Manag 2002:47:263-79.

13 Kaplan HS, Fastman BR. Organization of event reporting data for sense making and system improvement. Qual Saf Health Care 2003;12(Suppl II):ii68-72.

14 Edwards IR, Aronson JK. Adverse drug reactions: definitions, diagnosis, and management. Lancet 2000;356:1255-9.

15 Walshe K. Adverse events in health care: issues in measurement. Qual Health Care 2000;9:47-52.

16 Nebeker JR, Barach P, Samore MH. Clarifying adverse drug events: a clinician's guide to terminology, documentation, and reporting. Ann Intern Med 2004; 140:795-801.

17 Nebeker JR, Hurdle JF, Hoffman J, et al. Developing a taxonomy for research in adverse drug events: potholes and signposts. J Am Med Inform Assoc 2002;9(Suppl):S80-5.

18 Rubin G, George A, Chinn DJ, et al. Errors in general practice: development of an error classification and pilot study of a method for detecting errors. Qual Saf Health Care 2003;12:443-7.

19 Bates DW. Medication errors. How common are they and what can be done to prevent them? Drug Saf 1996;15:303-10.

20 Manasse HR Jr. Medication use in an imperfect world: drug misadventuring as an issue of public policy, Part 1. Am J Hosp Pharm 1989:46:929-44.

21 Case RL, Guzzetti PJ. A survey of adverse drug reaction reporting programs in select hospitals. Hosp Pharm 1986;21:423-38.

22 Kaushal R, Bates DW. Information technology and medication safety: what is the benefit? Qual Saf Health Care 2002;11:261-5

23 Bates DW, Boyle DL, Vander Vliet MB, et al. Relationship between medication errors and adverse drug events. J Gen Intern Med 1995; 10:199-205.

24 Morimoto T, Gandhi TK, Seger AC, et al. Adverse drug events and medication errors: detection and classification methods. Qual Saf Health Care 2004;13:306-14.

25 Troutman WG, Doherty KM. Comparison of voluntary adverse drug reaction reports and corresponding medical records. Am J Health Syst Pharm 2003:60:572-5. 